\title{
Identification of Risks and Estimation of Flood Storage in Ponds
}

\author{
Jianwei Liu and Can Zhang \\ School of Hydraulic Engineering, Dalian University of Technology, Dalian 116024, China \\ Correspondence should be addressed to Jianwei Liu; jwliu@dlut.edu.cn
}

Received 7 December 2016; Accepted 16 April 2017; Published 31 May 2017

Academic Editor: Anna M. Gil-Lafuente

Copyright (C) 2017 Jianwei Liu and Can Zhang. This is an open access article distributed under the Creative Commons Attribution License, which permits unrestricted use, distribution, and reproduction in any medium, provided the original work is properly cited.

\begin{abstract}
The article demonstrates methods for identification and assessment of risks for efficient utilization and storage of floodwater, which can be utilized in middle and lower reaches of rivers. Firstly, the methods of analytic hierarchy process and principal component analysis were proposed, which can identify the main risk factors and associated losses during the storage of floodwater in ponds. The major factors of risk include uncertainty of benefit losses, uncertainty of calculation methods and parameters, long-term rainfallrunoff forecasting errors, scheduling decision, and implementation. Next, a two-dimensional estimation model used to get the risk rate of flood storage in ponds during different stages of flood including scenarios with and without control measures is developed. The identified risk factors were applied on an event of rainfall $(200 \mathrm{~mm})$ to evaluate the risk of flood storage in Cile pond. To conclude, the laws of risk in terms of space and time are demonstrated as follows: (1) in spatial dimension, the risk involved will be higher if flood storage capacity is great, and, (2) in temporal dimension, the risk involved will be higher if storage occurred earlier than anticipated. This article further concludes that if flood storage is greater, the risk loss associated with control measures will obviously be smaller than that without control measures.
\end{abstract}

\section{Introduction}

The distribution of water resources is uneven on the temporal and spatial scales in China [1]. Approximately $70 \%$ of the rainfall mainly concentrates during the flood season in most regions of China. Next, the interannual variation of rainfall is obviously marked, which results in more serious shortage of water resources [2]. In some regions, this seasonal variation of rainfall also limits the economic and social development, which can create the issues of agricultural damage, the water and environmental pollution, the water scarcity and disputes, the industrial loss, and harm to the health of people. Water resources issues deserve to be resolved so as to serve the strategy of sustainable development [3]. Owing to the aforementioned issues, people have diverted their focus to store and utilize floodwater. Despite the fact that floodwater causes huge damage, it also plays an important role in solving water shortage and the uneven distribution of water resources in space and time. On the basis of successful increase in the number of practical cases, the new functions of floodwater are discussed in this article.

Currently, there are many methods for the utilization of floodwater [4-9]. Besides reservoirs, lakes, and rivers, the pond is another important geological pattern to store water. The flood storage in ponds, which are located in the middle and lower reaches of the rivers, is another main utilization of floodwater. This method not only alleviates flood damage but also restores the water for ecological environment and replenishes groundwater. Next, it brings direct benefits to the irrigated agriculture and to the fishery. To conclude, the proposed method is also significant for the regional development, the economic development, the social development, and the sustainable utilization of water resources. However, the risks and benefits of floodwater still coexist. The risks' presence arises from some uncertain factors, stemming from true randomness, and epistemic uncertainties, stemming from lack of knowledge [10]. If it is used inappropriately, it may incur huge losses. Figure 1 shows the utilization of stored floodwater in ponds. Keeping this in view, it is necessary to carry out the identification and evaluation about the risks during the process of flood storage in ponds, which can provide theoretical basis for both reducing and avoiding the risks during the utilization of floodwater. Based on the analysis of risk sources, this article selects the main risk factors for onward storage of 


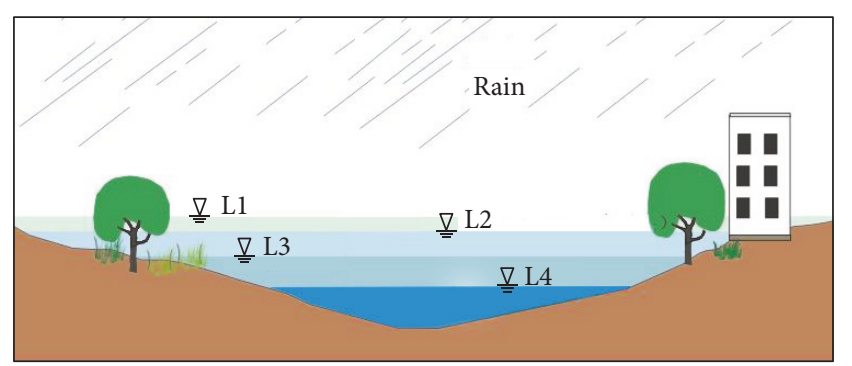

L1: after rainfall with flood input $\quad$ L2: after rainfall without flood input L3: after floodwater input L4: original water level

FIGURE 1: Schematic map of floodwater storage in the ponds.

floodwater in ponds, establishes estimation model of the risk of floodwater storage in ponds, and takes Cile pond in Baicheng city as an example.

\section{Identification of Risks and Evaluation of Flood Storage in Ponds}

The volume of floodwater in storage ponds is different because of their different functions. According to the main functions, storage ponds can be classified into "flood controlling ponds" and "non-flood controlling ponds." The former are located at the flood detention region and can mainly be used to control flood, whereas the associated risks depend on the uncertainty involved in the rainfall prediction during the flood seasons. The non-flood controlling ponds are used for flood storage. However, there are many problems related to non-flood controlling ponds when they will be used for flood storage, and these problems are the complex process of flood storage and the associated risks. Based on the analysis of these aspects, a model was built for the evaluation of risks of flood storage in ponds.

2.1. Identification of Main Risk Factors. The risks associated with the flood storage in ponds are mainly incurred due to a number of processes involved in flood storage. The three major stages required in the process of the flood storage are designing, dispatching, and implementation, of which designing is a general arrangement for the utilization of floodwater. The aim of designing is to effectively use the floodwater and to promote the economic development under safe conditions [11]. Designing includes (1) survey and evaluation of the present situation of water resources on a regional scale, (2) utilization plan for the establishment of water resources, (3) making plans, and (4) evaluation of the plans. During the second stage of dispatching, an optimal flood control plan was made on the basis of longterm runoff forecasting and the analysis of risk benefit [12]. In the implementation stage, a control plan to pool the resources achieved from floodwater was carried out to ensure the effective utilization of floodwater. This last stage also takes into account the early current background and the flood forecast results [11]. The system of risk factors for flood storage (see Figure 2) is constructed by analyzing both the work process and conditions of the three stages. Thereafter, according to Figure 2, the main risk factors of flood storage in ponds were selected as shown in the following subsections.

2.2. Screening of the Main Risk Factors. Up to now, storage of floodwater in ponds has not turned into a complete system; this is due to the lack of knowledge involved in risk accidents, insufficient data, and nonuniform standards for onward screening the main risk factors. To calculate the weight of each risk factor and to screen out the main components of primary risk factors involved during the storage of floodwater in ponds, the following techniques have been used in this article: (1) the method of analytic hierarchy process (AHP) and (2) the principal component analysis (PCA) for the integration of the selective standards. The specific steps involved in the aforementioned techniques are outlined in the following paragraphs:

Step 1 (the analytic hierarchy process). The method of analytic hierarchy process (AHP) has widely been used in multicriteria decision-making and weighting factors [13]. The analytic hierarchy process (AHP) decomposes complex decisions into structured smaller decisions, incorporates quantitative evidence and qualitative expert opinion, and promotes structured consensus building [14]. It can easily be grasped. AHP makes the assessment of the contribution of each factor easier and overcomes problems such as overlapping and interrelation between factors [15]. So, it is chosen to calculate the weight coefficient of each risk factor. The steps required in AHP are explained as follows:

(1) Construct all factors into one hierarchy structure. Target layer is the failure of flood storage in ponds and the corresponding risk factors (see Figure 2) are index layer.

(2) Complete the pairwise comparison matrices, that is, the judgment matrices. The instrument used in this article is based on a 9-point scale as proposed by Saaty, where "1" represents the equal importance of two criteria and " 9 " represents the highest importance of one factor over another factor (see Table 1).

(3) Use root method to calculate the eigenvalues and eigenvectors of each matrix and judge the consistency. The consistency ratio is the quotient of index for the random indices of the same-order matrix, which can define the accuracy of the pairwise comparison. This matrix is accepted when it is less than 0.10; otherwise the values in the comparison matrices need to be examined and adjusted. For example, pairwise matrix for the criteria (i.e., risk of design, risk of control plan, and risk of implementation) and the eigenvector of weights are calculated as shown in Table 2. Thereafter, different risk factors are compared in terms of each criterion in the usual way.

(4) Perform the general hierarchical sequencing (i.e., calculating the composite weight of each risk factor) and check its consistency. The composite weights of risk factors are obtained by the result of the multiplication 
TABLE 1: Scale for pairwise comparison.

\begin{tabular}{lll}
\hline Relative intensity & Definition & Explanation \\
\hline 1 & Of equal value & Two requirements are of equal value \\
3 & Slightly more value & Experience slightly favors one requirement over another \\
5 & Essential or strong value & $\begin{array}{l}\text { Experience strongly favors one requirement over another } \\
\text { A requirement is strongly favored and its dominance is } \\
\text { demonstrated in practice }\end{array}$ \\
7 & Very strong value & $\begin{array}{l}\text { The evidence favoring one over another is of the highest } \\
\text { possible order of affirmation }\end{array}$ \\
9 & Extreme value & $\begin{array}{l}\text { When compromise is needed } \\
\text { Intermediate values between the two adjacent }\end{array}$ \\
\hline
\end{tabular}

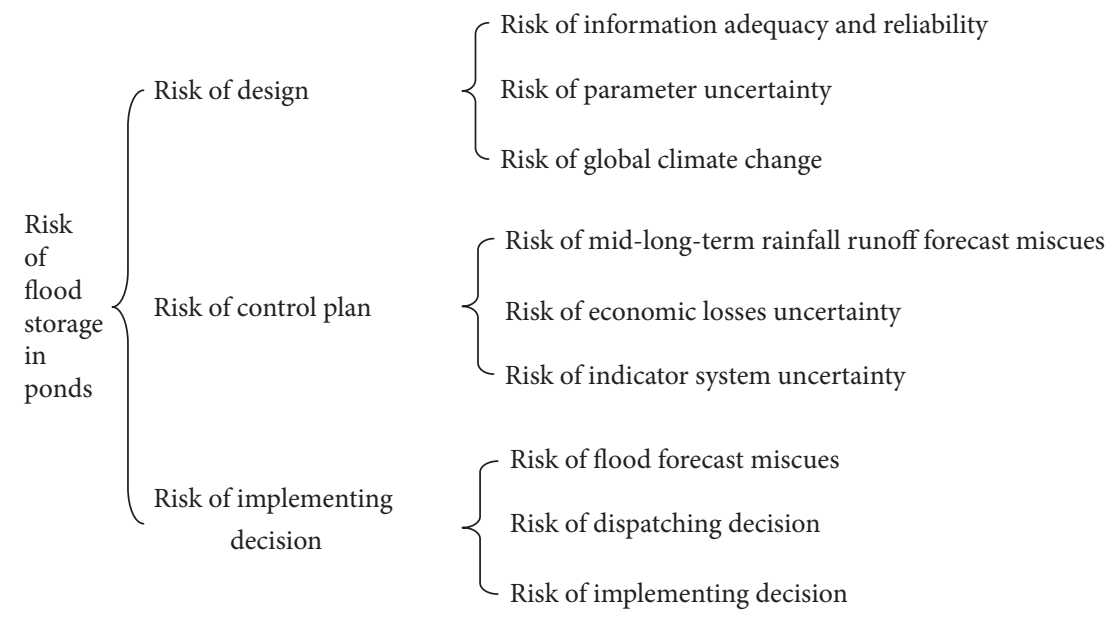

FIGURE 2: The system of risk factors for flood storage.

of each weight on the second level by its respective weight on the third level. These results are shown in Table 3.

Step 2. Principal component analysis (PCA) was used to calculate the cumulative contributions of different factors, which were expressed by the factor weights in a descending order.

In general, PCA usually requires the extraction of total amount of principal components to make its contribution value greater than 0.85 (see Table 4); the accumulation rate of the first five risk factors can reach up to $87.5 \%$. On this basis, the five factors are selected as major risk factors for the storage of floodwater in ponds. These factors are the benefits loss of uncertainty risk, the calculation methods and parameter uncertainty risk, the long-term rainfall-runoff forecast error risk, the dispatching decision-making risk, and the risk of the real-time operation.

2.3. The Risk Evaluation Model and Method. By combining the selected risk factors, the relationship between the risk rates and the storage capacity of ponds was analyzed. The preselected factors are grouped into three stages during the process of storage of floodwater in ponds. By using the probability theory, a two-dimensional risk evaluation model for the storage of floodwater is developed, which is based on the analysis of temporal and spatial dimensions and can mathematically be expressed as follows:

$$
\begin{aligned}
f\left(V_{i}, T_{j}\right)= & 1-\left(1-f_{1}\right) \times\left(1-f_{2}\left(T_{j}\right)-f_{3}\right) \\
& \times\left(1-f_{4}\left(V_{i}, T_{j}\right)-f_{5}\right),
\end{aligned}
$$

where $f\left(V_{i}, T_{j}\right)$ is the risk rate of the storage of floodwater in ponds; $f_{1}$ is the uncertain risk of the calculating methods and parameters; $f_{2}\left(T_{j}\right)$ is the uncertain risk rate of the loss of the effectiveness; $f_{3}$ is the risk rate of the error of long-term rainfall-runoff forecast; $f_{4}\left(V_{i}, T_{j}\right)$ is the risk rate of dispatching decision; $f_{5}$ is the risk rate of the realtime operation. The methods to calculate the risk rate of each factor, as defined above, are explained in the following subsections.

2.3.1. Uncertainty Risks for Evaluating the Methods and Parameters $\left(f_{1}\right)$. There are many parameter values that are hard to measure in an exact manner. Systematic and sampling errors occur in estimation of these parameters [16]. These values induce the uncertainty for evaluating the methods and parameters, for example, the selected methods for the longterm rainfall forecasting and for the value of pond storage of divisible flood volume. The risks are categorized differently 
TABLE 2: Pairwise matrix of the ratio of criteria to the objective and the criteria weights.

\begin{tabular}{lccccc}
\hline & Risk of design & Risk of control plan & Risk of implementation & Eigenvector weights & Consistency ratio \\
\hline Risk of design & 1 & $1 / 3$ & $1 / 3$ & 0.140 & 0.528 \\
Risk of control plan & 3 & 1 & 2 & 0.333 \\
Risk of implementation & 3 & $1 / 2$ & 1 & 0.046 \\
\hline
\end{tabular}

TABLE 3: The weight of risk factors of flood storage in ponds.

\begin{tabular}{|c|c|c|c|c|c|c|c|c|c|}
\hline \multirow[b]{2}{*}{$\begin{array}{l}\text { Risk of } \\
\text { flood } \\
\text { storage in } \\
\text { ponds }\end{array}$} & \multicolumn{3}{|c|}{ Risk of design } & \multicolumn{3}{|c|}{ Risk of control plan } & \multicolumn{3}{|c|}{ Risk of implementation } \\
\hline & $\begin{array}{c}\text { Risk of } \\
\text { information } \\
\text { adequacy } \\
\text { and } \\
\text { reliability }\end{array}$ & $\begin{array}{c}\text { Risk of } \\
\text { parameter } \\
\text { uncertainty }\end{array}$ & $\begin{array}{l}\text { Risk of } \\
\text { global } \\
\text { climate } \\
\text { change }\end{array}$ & $\begin{array}{c}\text { Risk of } \\
\text { rainfall and } \\
\text { runoff } \\
\text { forecast } \\
\text { miscues }\end{array}$ & $\begin{array}{c}\text { Risk of } \\
\text { indicator } \\
\text { system } \\
\text { uncertainty }\end{array}$ & $\begin{array}{c}\text { Risk of } \\
\text { economic } \\
\text { losses } \\
\text { uncertainty }\end{array}$ & $\begin{array}{l}\text { Risk of } \\
\text { flood } \\
\text { forecast } \\
\text { miscues }\end{array}$ & $\begin{array}{c}\text { Risk of } \\
\text { dispatching } \\
\text { decision }\end{array}$ & $\begin{array}{l}\text { Risk of } \\
\text { implement- } \\
\text { ing } \\
\text { decision }\end{array}$ \\
\hline Weight & 0.031 & 0.100 & 0.025 & 0.250 & 0.031 & 0.211 & 0.037 & 0.235 & 0.079 \\
\hline
\end{tabular}

due to different methods and parameter values, which are selected by the designers. Owing to these issues, the expert "scoring method" is used to evaluate the risks.

2.3.2. Uncertainty Risk of Benefit Loss $f_{2}\left(T_{j}\right)$. The uncertainty involved in estimating the ratio of benefit to loss for the storage of floodwater in ponds is mainly related to the aim of utilization of the stored floodwater. Generally, the floodwater resources stored in ponds are mainly used for irrigated agriculture and aquaculture. Therefore, the uncertainty involved in these losses can be expressed in terms of achieved gains for the agriculture and aquaculture. It can mathematically be expressed as follows:

$$
f_{2}\left(T_{j}\right)=k_{11} \times \mu_{A j}+k_{12} \times \mu_{F j},
$$

where $\mu_{A j}$ is the contribution towards the gains in agriculture during the period $j ; \mu_{F j}$ is the contribution towards the gains in aquaculture during the period $j ; k_{11}$ and $k_{12}$ are the corresponding weighting coefficients for agriculture and for aquaculture, respectively, which can be determined by the ratio of agricultural benefits to the aquaculture benefits.

2.3.3. Risk Rate of Long-Term Prediction Forecasting $\left(f_{3}\right)$. The processes of rainfall and runoff are influenced by many factors, such as astronomy, meteorology, physical geography, and human activities, which can probably be determined and randomized [17]. Although the application of mid-long term rainfall forecasting in different programs can reduce the risk for the storage of floodwater, the less accuracy problem of forecasting model may result in risks. This risk of rainfall forecasting may be attributed to the amount of estimated rainfall by excluding the actual rainfall.

2.3.4. Risk of Dispatching Decision $f_{4}\left(V_{i}, T_{j}\right)$. In case of the storage of floodwater in ponds, the dispatching decision (i.e., to ensure when and how to use floodwater based on the process of flood forecasting) for onward utilization of floodwater is influenced by many factors, that is, the precipitation, the rainfall-runoff forecasting, the dispatching management, and the error in decision-making. The decision-makers having different backgrounds (subject to their own experiences, objectives, and concepts) may make different decisions for scheduling the process [18]. By considering the actual process for the storage of floodwater in ponds, the risks involved in the dispatching decision are related to mid-long-term rainfall forecasting error rate and to the characteristics of local rainfall during the flood period. The mathematical expression can be written as follows:

$$
f_{4}\left(V_{i}, T_{j}\right)=P\left(V_{i}, T_{j}\right) \times f_{3},
$$

where $P\left(V_{i}, T_{j}\right)$ is the risk rate of overflow caused by the rainfall in the later period, when the storage capacity of the ponds is $V_{i}$. This can be expressed by using the frequency of cumulating rainfall corresponding to the rate of input flow which may fill the remaining volume of the ponds. It can be calculated by the following steps: (1) calculate the cumulative precipitation after flood storage in each of the following periods $\left(\sum R\right)$; (2) analyze the frequency of the accumulative precipitation in each of the following periods using the P-III curve; (3) the remaining volume of the ponds is filled with rainfall (i.e., $V-V_{i}$ ) provided that the volume of the ponds is $V$; (4) the frequency of the needed precipitation can be found during the analysis of P-III curve of the accumulative precipitation in each of the subsequent periods.

2.3.5. Risk Rate of the Real-Time Operation $\left(f_{5}\right)$. The risks involved in real-time operation are caused by the sudden failure for the storage of floodwater in the ponds, which might be attributed to the low-quality equipment and the difficulties incurred in communication. To measure these risks, expert "scoring method" can always be used.

\section{Case Study}

3.1. Study Area. This study was carried out in Baicheng city, which is located in the arid and semiarid region of the Western Jilin province of China. The mean annual precipitation measured at regional scale is approximately equal to $400 \mathrm{~mm}$. Due to the varying temporal distribution, the precipitation is mainly concentrated during the flood season (i.e., between June and August). Precipitation in the flood season accounts for about $80 \%$ of the annual precipitation [19]. From 1949 


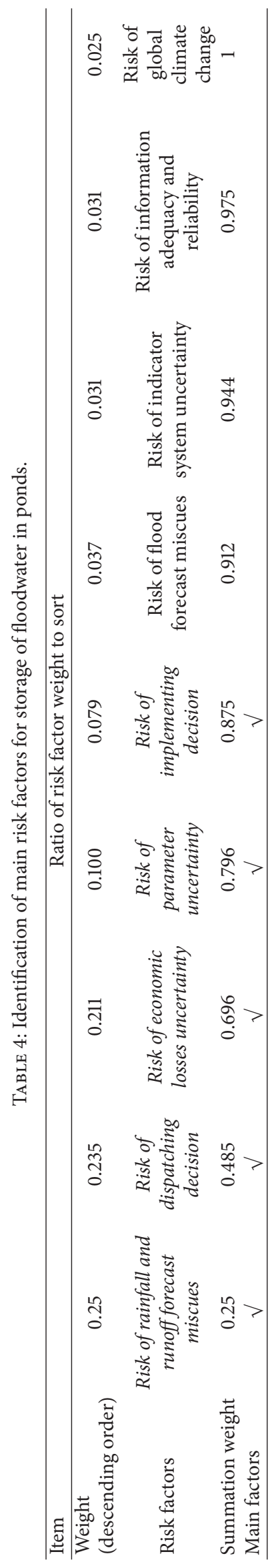




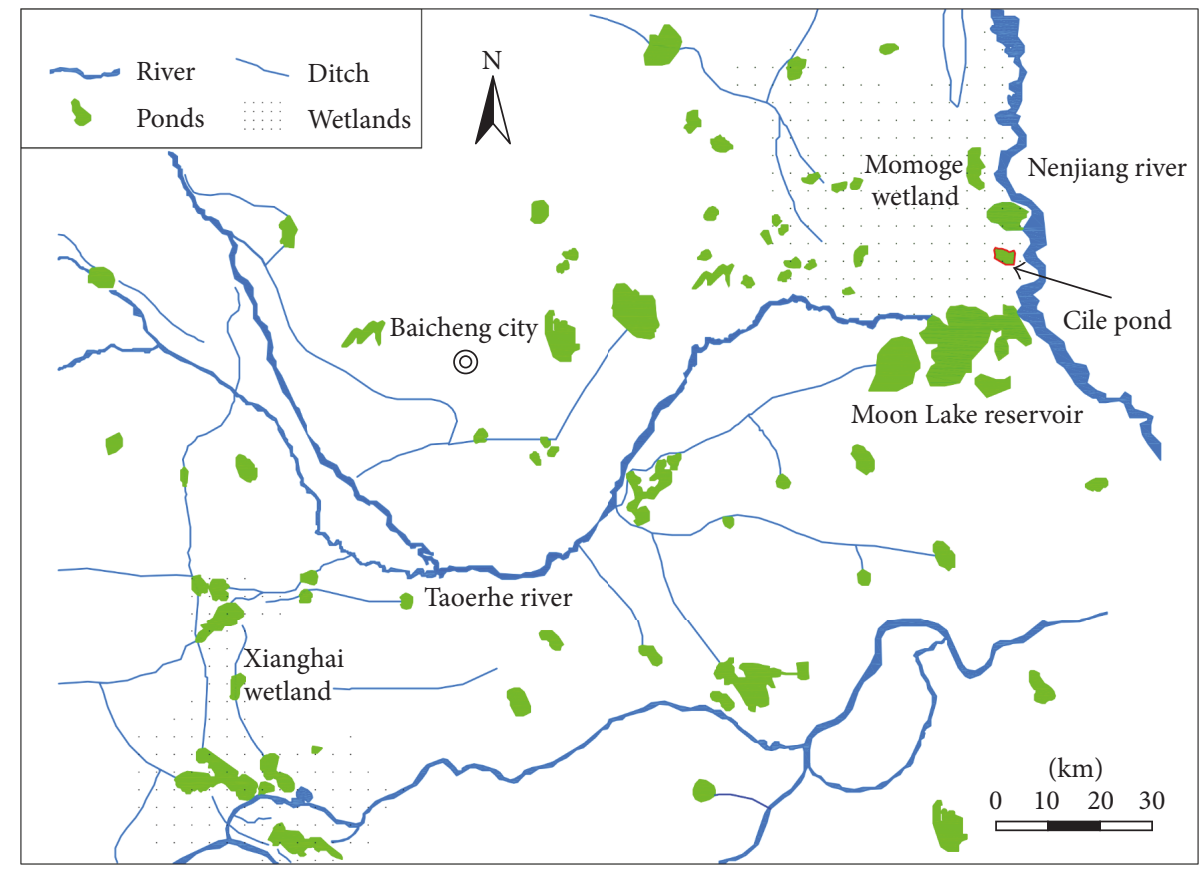

FIGURE 3: Distribution scheme of river system, flood diversion, and storage projects in Baicheng.

to date, the databases reveal that drought is a major climatic characteristic in Baicheng; the spring, summer, and autumn droughts were recorded approximately equal to $91.4 \%, 77.9 \%$, and $79 \%$, respectively. Keeping this in mind, the drought significantly influences the production, life, and environment and limits the regional economic development.

There are abundant extra water resources especially during the flood seasons due to the eight numbers of rivers including the one big river in Baicheng. The flood of Nenjiang river passes aside to Baicheng after the flood season, of which the intensity of streamflow is high and the duration of streamflow is long. The runoff of Nenjiang river during the flood season is approximately equal to $80 \%$ of Baicheng's annual runoff. Baicheng has abundant storage of floodwater, which includes reservoirs, wetlands, ponds, and underground reservoirs. There are two largesized reservoirs, Moon Lake and Xianghai reservoirs, six medium-sized reservoirs, and three small-sized reservoirs; their combined storage capacity is approximately equal to $1.8 \mathrm{bcm}$ (billion cubic meters), besides three great wetlands having a total area of approximately $15 \mathrm{bsm}$ (billion square meters). These three wetlands are Xianghai, Momoge, and Moon Lake (see Figure 3).

There are more than 700 ponds in Baicheng and their total area is approximately $0.8 \mathrm{bsm}$, of which only 71 ponds provide storage capacity more than $3.0 \mathrm{mcm}$ (million cubic meters), whereas their total volume is approximately $1.27 \mathrm{bcm}$. However, numerous ponds may either shrink or dry up and sometimes behave like a desert owing to the following facts: (1) the fact that the measures to store water are not being taken and (2) the continuous drought conditions. This article evaluates Cile pond (which contains total area approximately equal to $10 \mathrm{msm}$ [million square meters] and the possible storage capacity of water equal to $20 \mathrm{mcm}$ ) as an example for the storage of floodwater in ponds (see Figure 3 ).

\subsection{Risk Evaluation of Flood Storage in Cile Pond}

\subsubsection{Values of Main Risk Factors}

(1) Uncertainty Risk for Calculating the Methods and Parameters. Under this research work, the twenty experts were invited to reply to the predesigned questionnaire in which the various design parameters were evaluated on the scale ranging between 0 and 1 , where " 0 " means no risk and " 1 " means absolute risk, on the basis of which the probable risk factors and their likely influence on the model were also considered. To conclude, the aforementioned questionnaires give an average uncertainty of approximately $1 \%$ for calculating the methods and parameters.

(2) Uncertainty Risk of the Ratio of Benefit to Loss. Owing to the fact that the agricultural revenue is higher than the fishing revenue, $k_{11}$ and $k_{12}$ are assigned as 0.7 and 0.3 , respectively. The risk uncertainty of the benefit is calculated by considering the statistical results of agricultural and fishing revenues by using (2). The results are shown in Table 5.

(3) Risk of Mid-Long-Term Rainfall and Runoff Forecasting Error. According to the statistical results of the mid-longterm forecasting model, the frequency of rainfall forecasting error is $10 \%$ when actual precipitation is more than the predicted precipitation.

(4) Risk of Dispatching Decision. On the basis of daily precipitation data of Baicheng between 1951 and 2007, the cumulative precipitation between July and August was classified for the period of 10 days. Comparing the frequency between 
TABLE 5: Uncertainty risk of benefit calculation.

\begin{tabular}{lcccccc}
\hline Period & Early July & Mid-July & Late July & Early August & Mid-August & Late August \\
\hline Risk rate (\%) & 12.3 & 12.0 & 11.6 & 10.3 & 9.8 & 9.8 \\
\hline
\end{tabular}

TABLE 6: Factor index and grading for the project of flood control.

\begin{tabular}{|c|c|c|c|c|c|c|}
\hline Flood control project & Factor & Lower risk & Low risk & Intermediate risk & High risk & Higher risk \\
\hline Reservoir & Integrated risk rate $R_{0}$ & $0.00 \sim 0.25$ & $0.25 \sim 0.50$ & $0.50 \sim 0.75$ & $0.75 \sim 0.90$ & $0.90 \sim 1.00$ \\
\hline Flood diversion with dams & Risk degree $P_{f}$ & $0.00 \sim 0.25$ & $0.25 \sim 0.50$ & $0.50 \sim 0.75$ & $0.75 \sim 0.90$ & $0.90 \sim 1.00$ \\
\hline Flood area & Flood disaster risk degree $K$ & $0.00 \sim 0.25$ & $0.25 \sim 0.50$ & $0.50 \sim 0.75$ & $0.75 \sim 0.90$ & $0.90 \sim 1.00$ \\
\hline
\end{tabular}

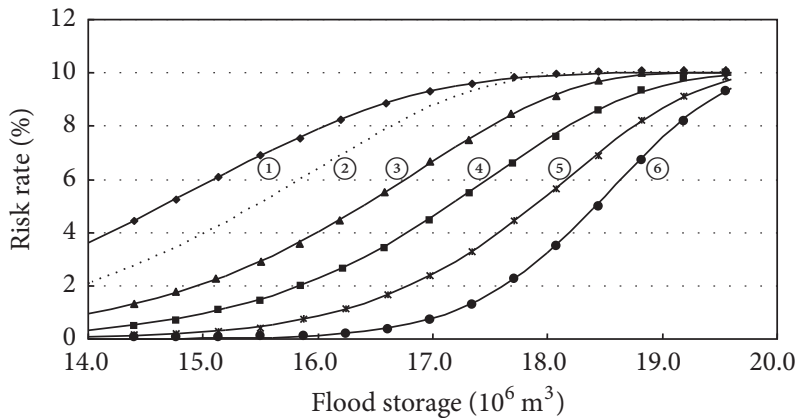
(1) Early July
(2) Mid-July
(3) Late July

\begin{abstract}
(4) Early August
(5) Mid-August

(6) Late August
\end{abstract}

FIGURE 4: Scheduling the decision risk in case of Cile pond.

the later part of cumulative precipitation by P-III curve and the precipitation used to fill the remaining volume of Cile pond after flood storage. The risk rate for scheduling decision of rainfall forecasting error can be calculated by using (3); the results of the risk rate for flood storage in different period are shown in Figure 4.

(5) Real-Time Operating Risk. On the basis of expert scoring method, the real-time operating risk is $5 \%$, which is the same as the uncertainty risk for calculating the methods and parameters.

3.2.2. Risk Evaluation. Risk values, involved in the storage of floodwater between July and August in Baicheng, were calculated by using (1). The achieved results are shown in Figure 5.

The risks involved in the storage of floodwater in Cile pond are regarded as variable during different periods of time and during storage of floodwater (see Figure 5). In case the storage of floodwater is same during different periods of the time, the risk rate can be sorted as follows:

Early July > mid-July > late July $>$ early August $>$ midAugust $>$ late August

Meanwhile, for the case of same period, the risk involved in the storage of floodwater increases as the storage increases. The risk level increases on a faster scale when the storage capacity exceeds a threshold value, that is, $17.2 \mathrm{mcm}$, during late August.

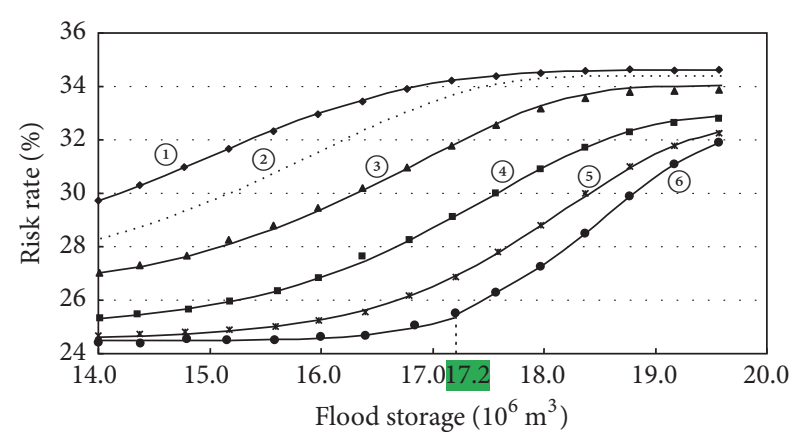
(1) Early July
(2) Mid-July
(4) Early August
(3) Late July
(5) Mid-August
(6) Late August

Figure 5: Flood storage risk in case of Cile pond.

On the basis of conclusions derived by Ji et al. [20], the risk grade of flood control for the storage of floodwater during the flood season in Cile pond is evaluated on (1) the basis of estimation of risk rate for the storage of floodwater, (2) the table of factor index, and (3) the grading for the project of flood control (see Table 6). One of the conclusions can be drawn from both Figure 5 and Table 6 and is as follows: the risk grade of Cile pond for the storage of floodwater between July and August is regarded as low risk.

\section{Conclusions}

On the basis of analysis of risks for the storage of floodwater in ponds, this article referred to the following main risk factors for the utilization of the floodwater: uncertainty risk for calculating the methods and parameters, uncertainty risk of the ratio of benefit to loss, risk of long-term rainfall and runoff forecasting error, risk of dispatching decision, and real-time operating risk. This article further built a two-dimensional model to evaluate the risks. Cile pond in Baicheng was taken as a case study to demonstrate the validity of aforementioned main risk factors and the model. On the basis of this research work, the following conclusions are derived:

(1) In accordance with the analysis for the utilization of the floodwater, the main factors for the storage of floodwater in ponds were selected by using PCA and AHP methods. These methods include an uncertainty risk for benefit loss, an uncertainty risk for 
the calculating methods and parameters, a risk of mid-long-term rainfall forecasting errors, a risk of dispatching decision, and a risk of real-time operation. The main risk factors, which contribute to risk rates, were sorted as follows:

Risk of mid-long-term rainfall forecast errors > risk of dispatching decision $>$ uncertainty risk of benefit loss > uncertainty risk for calculating the methods and parameters $>$ risk of real-time operation.

(2) A two-dimensional risk evaluation model, for the storage of floodwater in ponds, was built on the basis of dimensional analysis in space and time. On the basis of relationship between the remaining storage of floodwater in ponds and the possibility of precipitation in the following period, the aforementioned model provides a method for the utilization of floodwater in ponds and for the evaluation of risk, whereas the ponds were located at the middle and lower reaches of river.

(3) By means of analyzing the storage of floodwater in Cile pond, the risks in different periods of time for the same volume of storage were sorted as follows:

Early July $>$ mid-July $>$ late July $>$ early August $>$ mid-August $>$ late August.

Meanwhile, during the same period, the flood storage risk was increased by increasing the flood storage. On the basis of analysis, it is concluded that the aforementioned model of temporal and spatial dimensions can be treated as reasonable.

(4) If the storage in ponds occurred in the early flood season, then the storage would be great in volume and the associated risks might be on the higher side and vice versa. Next, the risk of flood storage is on the lower side during late August.

(5) Generally, the risks were less and the risk grades were on the lower side when the floodwater is stored in Cile pond between July and August. Keeping this in view, the most effective and safe utilization of the floodwater resources in ponds can be achieved on time by diverting the moderate floodwater and this is highly depending on the current situations and the flood forecasting.

The study for storage of floodwater in ponds is only in its infancy. Currently, there are no detailed facts and figures about the whole process. Next, the model of risk assessment could be established which is based on floodwater storage in real time. The risk can be evaluated by analyzing precipitation, runoff, time of flood storage, and control strategy of ponds in nature. And it will be possible to calculate the risk of the years ahead via long-term prediction forecasting for further research.

\section{Conflicts of Interest}

The authors declare that there are no conflicts of interest regarding the publication of this paper.

\section{Acknowledgments}

This research is supported by the National Natural Science Foundation of China (51679026 and 51209030) and the National Key Research and Development Program of China (2016YFC0400903).

\section{References}

[1] Y. X. Wei and L. X. Wang, Engineering Hydrology, Hydraulic and Hydroelectricity, Water Conservancy and Electricity Press, Beijing, China, 2005.

[2] G. Z. Du, The Study of Flood Resources Management, Dalian University of Technology, Dalian, China, 2005.

[3] H. Wang and J. H. Wang, "Sustainable utilization of China's water resources," Bulletin of the Chinese Academy of Sciences, vol. 27, no. 3, pp. 352-358, 2012.

[4] J. J. Xu, D. X. Wu, and J. J. Huo, "Preliminary discussion on approaches and measures of flood utilization in the Yangtze River Basin," Yangtze River, vol. 39, no. 15, pp. 1-4, 2008.

[5] C. A. Li, "Possible floodwater utilization of the Yangtze river," Earth Science-Journal of China University of Geosciences, vol. 28, no. 4, pp. 461-466, 2003.

[6] F. Feng and W. J. Sun, "Approach to ways and means for reclamation of floods," Soil and Water Conservation in China, no. 9, pp. 4-5, 2005.

[7] W. Lee, Flood Utilization Mode and Its Risk Analysis, Wuhan University, Wuhan, China, 2004.

[8] W. B. Xiao, B. H. Wang, and Q. F. He, "Research on utilization of flood resources in Xiao Huangni River," Perl River, vol. 36, no. 6, pp. 9-11, 2015.

[9] X. Y. Wu, S. M. Zhong, and H. S. Zhang, “The main measures of flood resources utilization," Heilongjiang Science and Technology of Water Conservancy, vol. 41, no. 3, pp. 170-171, 2013.

[10] R. B. Jongejan and B. Maaskant, "Quantifying flood risks in the Netherlands," Risk Analysis, vol. 35, no. 2, pp. 252-264, 2015.

[11] J. W. Liu, Study on river floodwater resources utilization in plain area, Dalian University of Technology, Dalian, China, 2007.

[12] J. W. Liu, S. G. Xu, and X. N. Wang, "Research on preplanning of floodwater resources utilization-a case study in baicheng," South-to-North Water Transfers and Water Science \& Technology, vol. 7, no. 3, pp. 67-70, 2009.

[13] O. S. Vaidya and S. Kumar, "Analytic hierarchy process: an overview of applications," European Journal of Operational Research, vol. 169, no. 1, pp. 1-29, 2006.

[14] M. Agapova, B. W. Bresnahan, K. F. Linnau et al., "Using the analytic hierarchy process for prioritizing imaging tests in diagnosis of suspected appendicitis," Academic Radiology, vol. 24 , no. 5 , pp. $530-537,2017$.

[15] S. Stefanidis and D. Stathis, "Assessment of flood hazard based on natural and anthropogenic factors using analytic hierarchy process (AHP)," Natural Hazards, vol. 68, no. 2, pp. 569-585, 2013.

[16] M. Behrouz and S. Alimohammadi, "Risk-based design of flood control systems considering multiple dependent uncertainties," 
Water Resources Management, vol. 30, no. 13, pp. 4529-4558, 2016.

[17] B. D. Wang, Fuzzy Mathematics Method for Mid-Long Term Hydrological Forecast, Dalian University of Science \& Technology Press, Dalian, China, 1993.

[18] R. E. Morss, O. V. Wilhelmi, M. W. Downton, and E. Gruntfest, "Flood risk, uncertainty, and scientific information for decision making: lessons from an interdisciplinary project," American Meteorological Society, vol. 86, no. 11, pp. 1593-1601, 2005.

[19] J. W. Liu, X. Li, and B. L. Zhang, "The current water resource situations and strategies of flood utilization in Baicheng City," Jilin Water Resources, no. 7, pp. 51-54, 2014.

[20] C. M. Ji, J. Q. Li, and Y. S. Zhang, "Matter-element model of integrated risk evaluation for flood-control engineering system," Journal of North China Electric Power University, vol. 32, no. 1, pp. 86-90, 2005. 


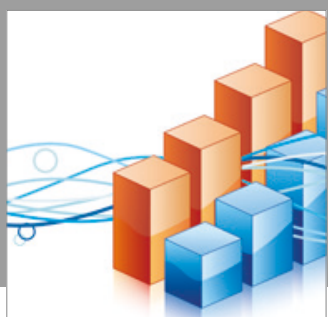

Advances in

Operations Research

vatersals

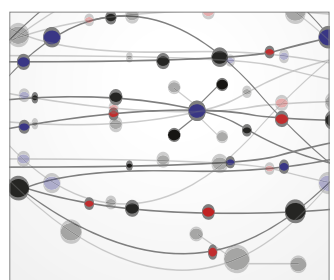

\section{The Scientific} World Journal
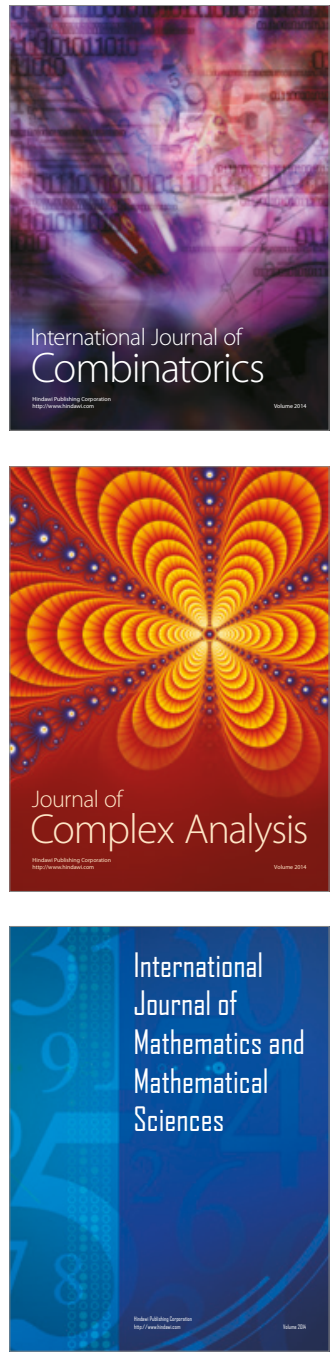
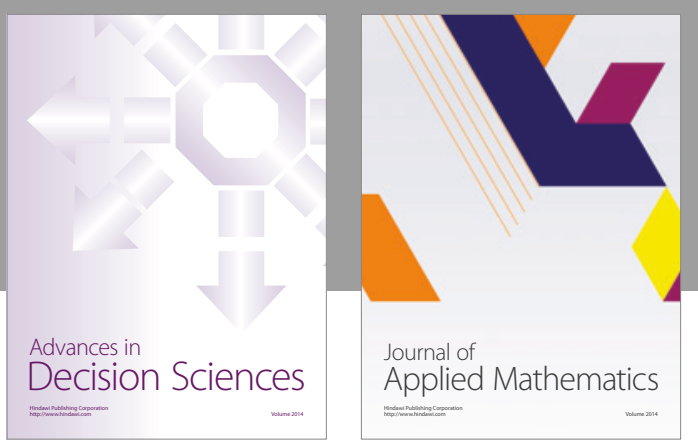

Algebra

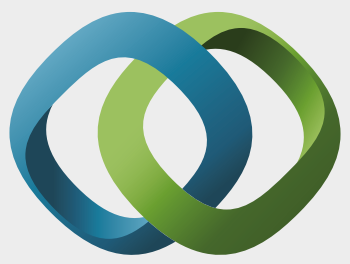

\section{Hindawi}

Submit your manuscripts at

https://www.hindawi.com
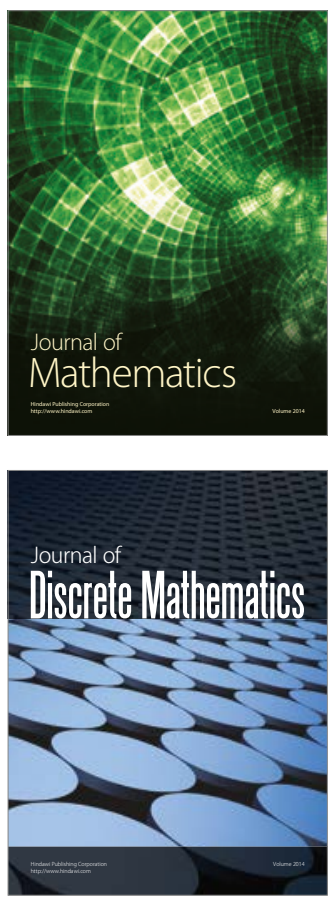

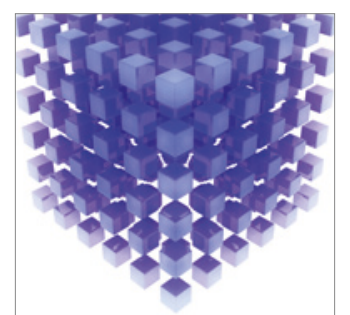

Mathematical Problems in Engineering
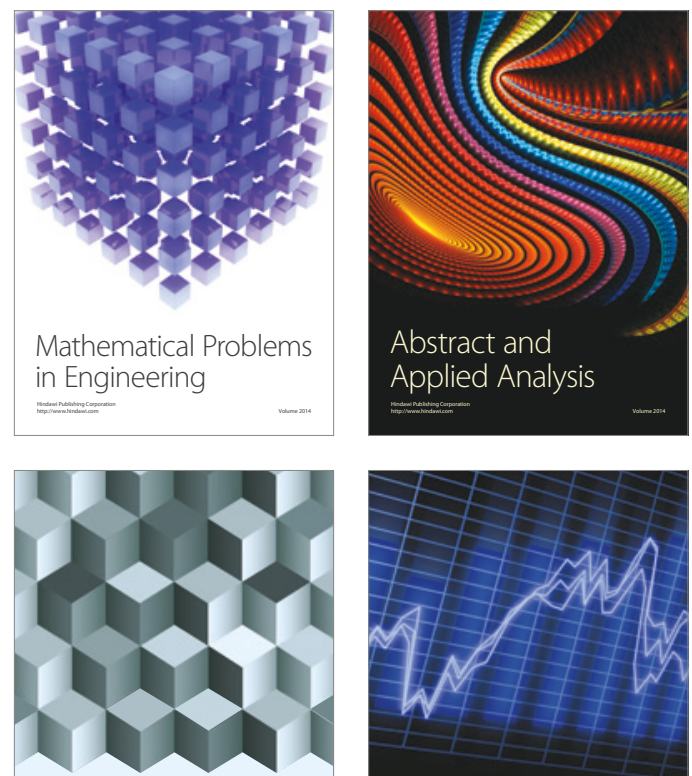

Journal of

Function Spaces

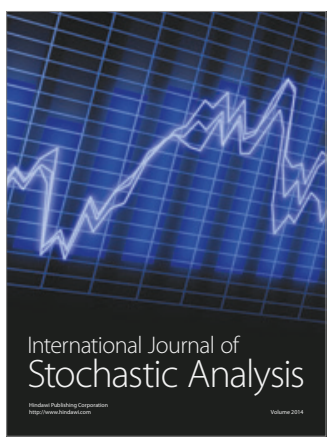

Probability and Statistics
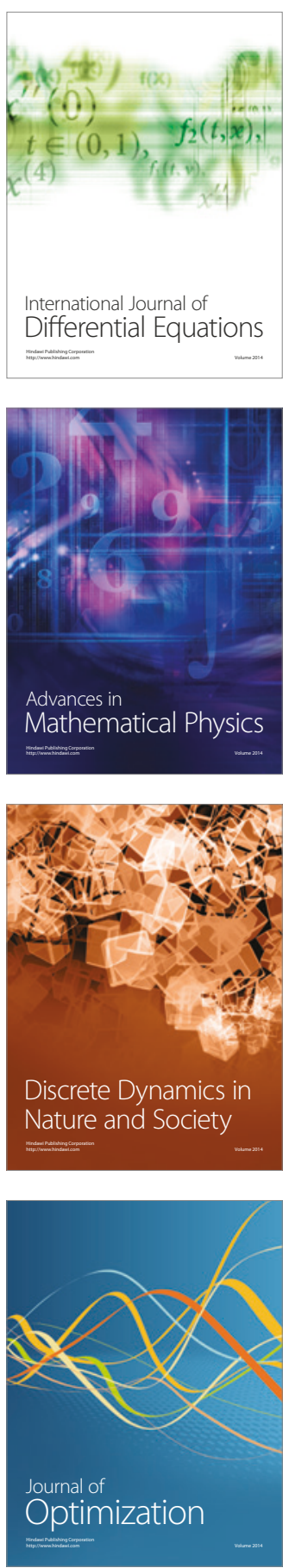